\title{
45 Years of the Journal Geotectonics
}

DOI: $10.1134 / \mathrm{S} 0016852110010012$

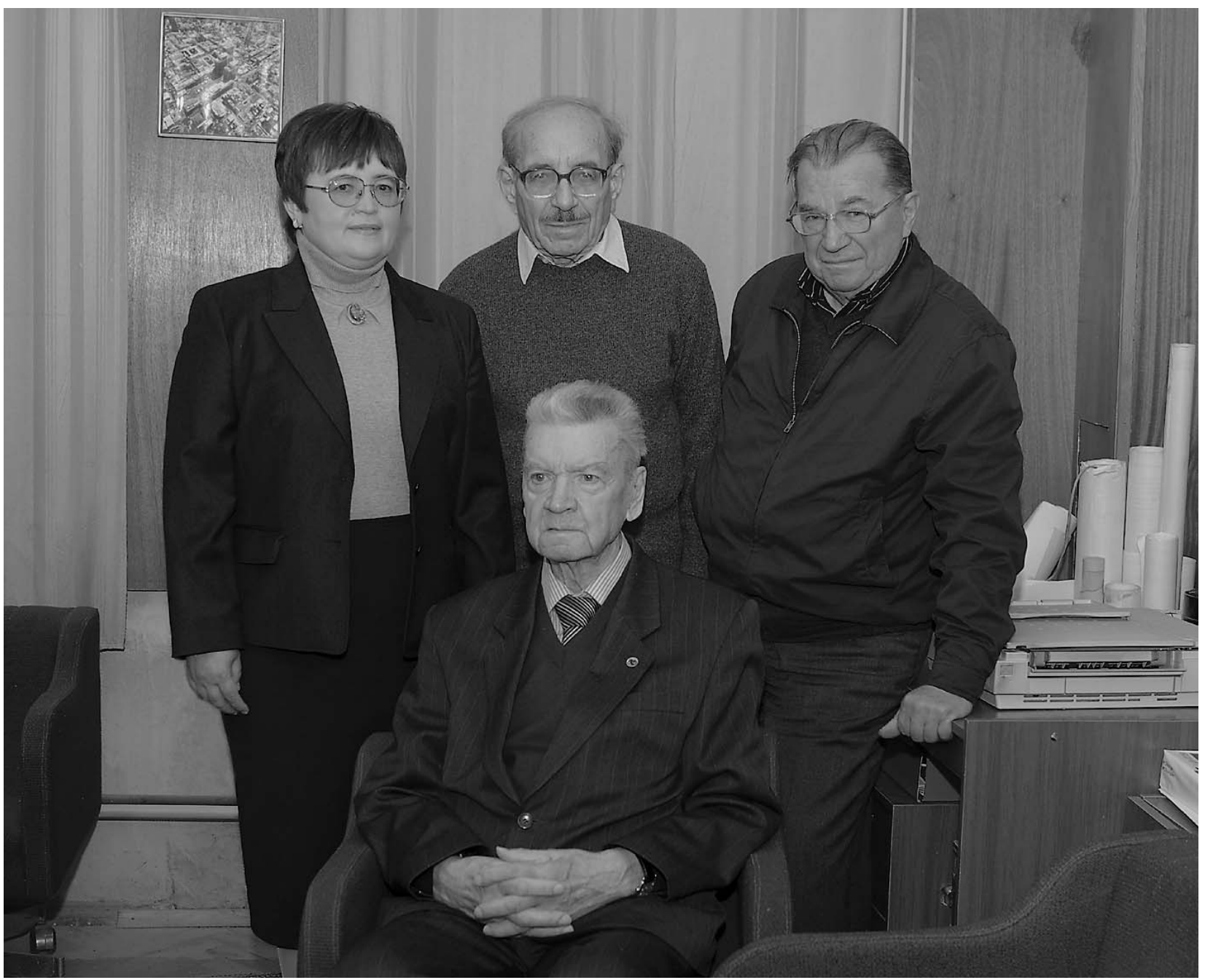

Fig. 1. Academician Yu.M. Pushcharovsky, editor-in-chief of the journal Geotectonics (sitting); M.N. Shupletsova, head of the editorial staff; V.S. Burtman, executive secretary; and S.V. Ruzhentsev, deputy editor in-chief (from left to right).

The first issue of the journal Geotectonics appeared in print in January 1965 as a response of scientific community and the management of the Academy of Sciences of the USSR to the great interest in geotectonics aroused by its advance at regional and global levels, especially in the 1950s, when the compilation of the tectonic maps of spacious territories started to develop.
Substantial results were also achieved before the World War II, particularly as concerns the regional tectonics of our country. The publications covered the results obtained were insufficient, and the decision was made to issue a specialized journal entitled Geotectonics.

M.V. Muratov, outstanding geologist, corresponding member of the Academy of Sciences of the USSR, was 


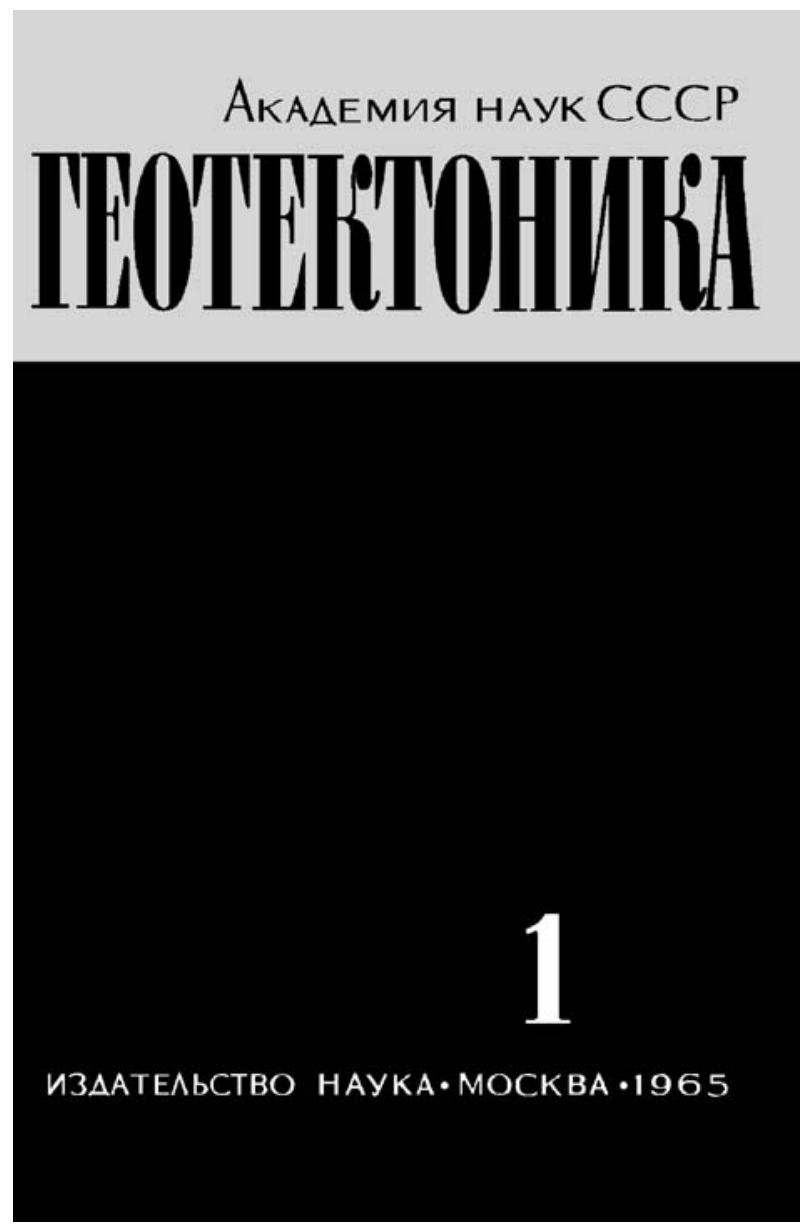

Fig. 2. Cover of the first issue of the journal Geotectonics.

confirmed to the editor-in-chief of the journal. After his decease in 1982, I was charged with this office.

Throughout the existence of the journal, its work proceeded without crises. The journal publishes papers on various fields of tectonic research. All papers are preliminarily considered by editorial board in respect of their scientific value.

The situation with subscription is rather good. The journal's rating is estimated at 0.5 . It would be desired to raise the rating. By financial reasons, the number of subscribers to electronic version of the journal recently increases at the expense of subscribers to hardcopies. Nevertheless, the total number of subscribers became greater than in preceding years.

In conclusion, I would like to note with gratitude the well-organized work of the editorial board, which maintains high prestige of the journal in the wide circle of geologists.

Yu. M. Pushcharovsky 